\title{
Effectiveness of intravenous iron sucrose over oral iron therapy for anaemia in pregnancy
}

\section{Devdatt Laxman Pitale*}

Department of Obstetrics and Gynecology, INHS Patanjali, Karnataka, India

Received: 10 March 2018

Accepted: 03 April 2018

\section{*Correspondence:}

Dr. Devdatt Laxman Pitale,

E-mail: dipu.pitale@gmail.com

Copyright: (C) the author(s), publisher and licensee Medip Academy. This is an open-access article distributed under the terms of the Creative Commons Attribution Non-Commercial License, which permits unrestricted non-commercial use, distribution, and reproduction in any medium, provided the original work is properly cited.

\begin{abstract}
Background: Anaemia in pregnancy is very common throughout our country impacting both mother and the newborn. The most common cause of anaemia in pregnancy is iron deficiency. The increased prevalence of iron deficiency anaemia amongst the pregnant women, especially in developing countries is a major cause of significant maternal morbidity and mortality. Intolerance to oral iron, inadequate absorption, and side effects leading to poor compliance are the major shortcomings in oral iron therapy. These factors are significant especially in anaemia near term. To overcome all these limiting factors associated with oral iron therapy, parenteral iron therapy is preferred. Aim of this study was to study effectiveness of intravenous iron sucrose over oral iron therapy for anaemia in pregnancy.

Methods: This prospective study was taken up to compare the effectiveness of intravenous iron sucrose over oral iron therapy for anaemia in 30 antenatal women attending antenatal outpatient Department of Obstetrics and Gynaecology belonging to gestational age group of 28-34 weeks with anaemia in pregnancy.

Results: Majority of pregnant women belonged to age group of 22-25 years.67\% were primigravidas. The period of gestation varied from 28-34 weeks. In this study, the mean baseline haemoglobin was $8.4 \mathrm{~g} / \mathrm{dl}$ before start of treatment and after iv iron sucrose treatment haemoglobin showed a mean value of $10.8 \mathrm{~g} / \mathrm{dl}$. The mean baseline MCV was $70 \mathrm{fl} /$ cell. Post treatment MCV after 4 weeks showed a significant mean rise of $12 \mathrm{fl} /$ cell in the present study with no major side effects.

Conclusions: Intravenous iron sucrose is highly effective over oral iron therapy for anaemia in pregnancy. It enables rapid correction of anaemia with minimal side effects.
\end{abstract}

Keywords: Haemoglobin, Iron deficiency anaemia, Mean corpuscular volume, Packed cell volume

\section{INTRODUCTION}

Anaemia in pregnancy is very common throughout our country impacting both mother and the newborn. It affects nearly half of all pregnant women in the world. ${ }^{1,2}$ The most common cause of anaemia in pregnancy is iron deficiency. ${ }^{3}$ The increased prevalence of iron deficiency anaemia amongst the pregnant women, especially in developing countries is a major cause of significant maternal morbidity and mortality. It contributes to about $20 \%$ of all maternal deaths and $9 \%$ of peri-natal mortality. ${ }^{4-6}$ Anaemia in pregnancy is significantly associated with preterm births, IUGR, PPH, failure of lactation, perinatal mortality and increased risk of infections. ${ }^{7,8}$ Correction of anaemia reduces maternal morbidity significantly and promotes better neurological development of new born/infants and improve the health status of women. 
Oral iron therapy has been the first line treatment modality for anaemia in pregnancy. Intolerance to oral iron, inadequate absorption, and side effects leading to poor compliance are the major shortcomings in oral iron therapy. These factors are significant especially in anaemia near term. To overcome all these limiting factors associated with oral iron therapy, parenteral Iron therapy is preferred.

According to the World Health Organisation (WHO), technical group working on the prevention and treatment of anaemia parenteral iron therapy produces a rapid and complete correction of iron deficiency anaemia than oral iron therapy. ${ }^{1}$ Amongst all the parenteral iron preparations available today, iron sucrose appears to be efficient, safe and overcomes the problems of absorption and compliance as compared to iron dextran, iron gluconate and also blood transfusion. ${ }^{9,10}$

\section{Pharmacology of iron sucrose $e^{11}$}

\section{Chemical formula}

$\left[\mathrm{Na}_{2} \mathrm{Fe}_{208}(\mathrm{OH})_{3}\left(\mathrm{H}_{2} \mathrm{O}\right)\right]$ n. $\mathrm{m}\left(\mathrm{C}_{12} \mathrm{H}_{22} \mathrm{O}_{11}\right)$. Iron sucrose is a brown, sterile, aqueous complex of polynuclear iron (III) hydroxide in sucrose containing $20 \mathrm{mg}$ elemental iron per $\mathrm{ml}$ with an osmolarity of $1250 \mathrm{mosm} / \mathrm{l}$.

\section{Molecular weight}

34,000-60,000 daltons.

\section{Mechanism of action}

Following intravenous administration, it is dissociated into iron and sucrose by reticuloendothelial system and iron is transferred from the blood into pool of iron in the liver and bone marrow. Ferritin sequesters iron in a nonionic form from which iron is easily available.

\section{Method and route of administration ${ }^{12}$}

Either as a bolus dose undiluted over 5-10 $\mathrm{min}$ ( $1 \mathrm{ml} / \mathrm{min}$ ) on outpatient basis (Rapid push) or as an Infusion for a short duration of $15-20 \mathrm{~min}, 200 \mathrm{mg}$ in $200 \mathrm{ml}$ of Normal Saline only (as other crystalloids cause precipitation or drug interaction) immediately after dilution. Maximum cumulative doses $1600 \mathrm{mg}$ in pregnancy (200mg twice per week to a target $\mathrm{Hb}$ of $11 \mathrm{~g} / \mathrm{dl}$ or for a maximum of 4 weeks).

Prompt and adequate treatment of Iron deficiency anaemia in pregnancy is essentially important to reduce the anaemia related morbidity and mortality.

\section{METHODS}

The present prospective study was taken up to compare the effectiveness of intravenous iron sucrose over oral iron therapy for anaemia in 30 antenatal women attending antenatal outpatient department at INHS Patanjali. Total duration of the study was 6 months.

\section{Inclusion criteria}

- Singleton pregnancy with gestational age of 2834weeks.

- Haemoglobin concentration of more than $8 \mathrm{~g} / \mathrm{dl}$ and less than $10.5 \mathrm{~g} / \mathrm{dl}$.

\section{Exclusion criteria}

- Pregnancy associated with comorbidities like Diabetes, heart disease, renal and hepatic disorders.

- Obstetrical complications like PIH, APH.

- Pregnancy with anaemia other than iron deficiency.

- Multifoetal gestation.

\section{Materials used for the study}

A total of 30 antenatal women in the age group of 20-30 years, who satisfied the inclusion criteria were included in the present study.

Investigations like complete haemogram, with all indices Haemoglobin (Hb\%), Packed Cell Volume (PCV), Mean corpuscular Volume (MCV), M.C.H.C, Reticulocyte count, Platelet count, Liver function tests, Serum Creatinine, blood urea, bleeding time, clotting time, and Random Blood Sugar (RBS) and Ultrasonography (USG) were being carried out to rule out exclusion criteria. Detailed history was elicited along with clinical examination. The Study group received iron sucrose intravenously, the dose was calculated using the following formula,

$2.4 \times \mathrm{Hb}$ deficit in $\mathrm{gm} \% \times$ body weight in $\mathrm{kgs}+500$ mg. ${ }^{12,13}$

Extra $500 \mathrm{mg}$ was to replenish iron reserves. Thus, obtained dose is given in divided doses, 300mg each time with minimum $48 \mathrm{hrs}$ apart. Each $\mathrm{ml}$ contains $20 \mathrm{mg}$ of elemental iron. Every $5 \mathrm{ml}$ of it is dissolved in $200 \mathrm{ml}$ of $0.9 \%$ of Normal saline per day. All these antenatal women were reviewed after 3-4 weeks with emphasis on improved sense of wellbeing, compliance and adverse effects if any. The blood indices were repeated to assess the response to parenteral iron therapy during the review.

\section{RESULTS}

The results were analysed as improvement in Blood indices, before and after taking I.V. Sucrose along with the mean rise in Haemoglobin (hb), MCV and Heamatocrit (PCV)from baseline. Demographic data is shown in (Table 1).

As Shown in Table 1, mean weight of the study group was $48 \mathrm{kgs}$ and most of them belonged to age group of 
22-25 years. The mean gestational age in the present study was of 30 weeks.

Table 1: Demographic data.

\begin{tabular}{|llll|}
\hline Parameter & Minimum & Maximum & Mean \\
\hline Weight & 40 & 60 & 48 \\
\hline Age & 20 & 30 & 24 \\
\hline Gestational age & 28 & 34 & 30 \\
\hline
\end{tabular}

As shown in Table 2, $67 \%$ of the antenatal women were Primi gravida. Only 10 in the study group were second gravidas.

Table 2: Distribution of Parity.

\begin{tabular}{|lll|}
\hline Gravida & Number & Percentage \\
\hline PRIMI & 20 & $67 \%$ \\
\hline G-2 & 10 & $33 \%$ \\
\hline Total & 30 & $100.00 \%$ \\
\hline
\end{tabular}

The above table shows us the improvement of MCV following parenteral iron therapy.

There has been a significant increase of $17 \%$ in $\mathrm{MCV}$ following IV iron sucrose.

Table 3: Distribution and comparison of MCV before and after treatment.

\begin{tabular}{|l|llll|}
\hline Group & At & Min. & Max. & Mean \\
\hline IV & $\begin{array}{l}\text { Before } \\
\text { treatment }\end{array}$ & 60 & 80 & 70 \\
\hline Sucrose & $\begin{array}{l}\text { After } \\
\text { treatment }\end{array}$ & 80 & 90 & 82 \\
\hline
\end{tabular}

Table 4: Distribution and comparison of mean haemoglobin before and after treatment.

\begin{tabular}{|ll|l|ll|}
\hline Group & At & Minimum & Maximum & Mean \\
\hline IV & Before & 8.0 & 9.0 & 8.4 \\
\cline { 2 - 5 } Sucrose & After & 10.0 & 12 & 10.8 \\
\hline
\end{tabular}

$10.8 \mathrm{~g} \%$ after treatment and therefore a rise by $2.4 \mathrm{~g} \%$ in 4 weeks. This is highly significant rise in mean $\mathrm{Hb}$ as shown in Table 4.

Table 5: Distribution and comparison of mean PCV (haematocrit) before and after treatment.

\begin{tabular}{|lllll|}
\hline Group & At & Min. & Max. & Mean \\
\hline IV & Before & 20 & 30 & 26.0 \\
\cline { 2 - 5 } Sucrose & After & 30 & 40 & 34.0 \\
\hline
\end{tabular}

Thrombophlebitis and pain at the site of injection are the adverse effects seen with iron sucrose injections. These adverse effects were not seen in any of the antenatal women in this study group.

\section{DISCUSSION}

Iron deficiency anaemia is the one of the most common and important public health problem globally, affecting about $56 \%$ of pregnant women in developing countries and $18 \%$ of women from industrialized countries. Anaemia in pregnancy is a leading cause of maternal and perinatal mortality. Anaemia is a known risk factor for preterm births, IUGR, PPH, failure of lactation and infections in post-partum period. Prevention and prompt correction of anaemia in pregnancy is vital for healthy and safe motherhood.

The conventional treatment modalities for anaemia in pregnancy include oral iron therapy and blood transfusion, especially in anaemia near term. This treatment options have serious limiting factors. High doses of oral iron frequently cause side effects like constipation, diarrhoea and noncompliance is very common. Oral iron supplementations is not sufficient enough to treat anaemia effectively, owing to the limited absorption, the gastrointestinal symptoms and the poor compliance.

Inherent risk of infections (bacterial, viral, prions) and immune modulation associated with allergenic blood products, especially in this young and otherwise healthy population, transfusions are used only in the most severe cases and particularly in life threatening situations. Therefore, intravenous iron has been considered as an highly effective alternative in the management of iron deficiency anaemia in pregnancy with a known safety profile.

In the present study, Majority of women were in the age group of 22-25 years. Mean age of the patients in other studies were approximately similar to present study.

In all other studies maximum number of patients were primigravidas. In the present study $67 \%$ were primi gravidas. This is explained by high prevalence of iron deficiency anaemia in adult non pregnant women, when these anaemic women become pregnant their anaemia will be aggravated by increased need of iron during pregnancy. Thus, it is extremely important to screen for iron deficiency anaemia in all non-pregnant women belonging to reproductive age group.

In the present study the mean gestational age at the time of inclusion in the study group is comparable (30 weeks) to the mean gestational age in the study by Aggarwal R S et al where it was 28.2 weeks. The mean baseline MCV was $70 \mathrm{fl} /$ cell. Post treatment MCV after 4 weeks showed a significant mean rise of $12 \mathrm{fl} / \mathrm{cell}$ in the present study.

In this study, the mean baseline haemoglobin was $8.4 \mathrm{~g} / \mathrm{dl}$ before start of treatment and after iv iron sucrose treatment haemoglobin showed a mean value of $10.8 \mathrm{~g} / \mathrm{dl}$. 
In the present study, the average rise of haemoglobin is $2.4 \mathrm{~g} / \mathrm{dl}$ which is comparable to the study by Aggarwal $\mathrm{R}$ $\mathrm{S}$ et al, where the average rise of haemoglobin was 5.03 $\mathrm{g} / \mathrm{dl}$ in intravenous group. ${ }^{14}$

Similarly, in the study conducted by Kharde et al, the average rise of haemoglobin was $3.54 \mathrm{~g} / \mathrm{dl}$ and $5.3 \mathrm{~g} / \mathrm{dl}$ in oral and IV group respectively with no major side effects in any of the cases. ${ }^{15}$

With all these studies, it is clearly evident that there is an effective rise in hemoglobin level with Intravenous iron Sucrose. The mean base line haematocrit (PCV) is $26 \%$ and post treatment mean PCV improved to $34 \%$ which is highly reassuring.

There were no major side effects in the study group. Similar observations were reported in other studies by Khade et al. ${ }^{15-17}$

\section{CONCLUSION}

Intravenous iron sucrose is highly effective over oral iron therapy for anaemia in pregnancy. It enables rapid correction of anaemia with minimal side effects. Known safety and a better efficacy profile, makes it an effective alternative for oral iron in treatment of anaemia in pregnancy.

\section{ACKNOWLEDGMENTS}

Author would like to acknowledge the support of his colleagues at INHS Patanjali, especially the Pathology Department for the completion and success of this study.

Funding: No funding sources Conflict of interest: None declared

Ethical approval: The study was approved by the Institutional Ethics Committee

\section{REFERENCES}

1. World Health Organization/United Nations University/UNICEF. Iron deficiency anaemia, assessment, prevention and control: a guide for programme managers.Geneva: WHO; 2001.

2. Noronha JA, Bhaduri A, Bhat VH. Prevalence of anemia among pregnant women: A communitybased study in Udupi. Health and Population Perspectives and Issues. 2008;31(1):31-40.
3. Haider BA. Anaemia, prenatal iron use, and risk of adverse pregnancy outcomes: systematic review and Meta-analysis. BMJ. 2013;346:f3443.

4. Ivan EA, Mangaiarkkarasi A. Evaluation of Anaemia in booked antenatal mothers during the last trimester. J Clin Diag Res. 2013;7(11):2487-90.

5. Rajagopal K. A study to assess the pregnant women the knowledge and risk factors of anaemia among the pregnant women selected and attending Healthcare facilities in Sebha, Libya. J Sci. 2014;4(1):19-22.

6. Patra S. Maternal and perinatal outcome in patients with severe anaemia in pregnancy. Int $\mathbf{J}$ Gynaecol Obstet. 2005;91:164-5.

7. Kalaivani K. Prevalence and consequences of anaemia in pregnancy. Indian J Med Res. 2009;130(5):627-33.

8. Scholl TO. Iron status during pregnancy: setting the stage for mother and infant. Am J Clinc Nutr. 2005;81:1218S-22S.

9. Scot BS, George MR. Parental iron therapy option. Am J. 2004;76:74-8.

10. Chandler G, Harchowal J, Macdougall IC. Intravenous iron sucrose: establishing a safe dose. Am J Kidn Dis. 2001;38:988-91.

11. Hinchingbrooke Health Care NHS Trust. Protocol for the use of IV iron sucrose-Venofer. NHS; 200.

12. Dutta DC. Medical illness complicating pregnancy. Textbook of Obstetrics, Ed. Konar H. $6^{\text {th }}$ edition. The central Book Agency Pvt Ltd. Culcutta; 2004:262271.

13. Dewan B. Assessment of intravenous iron sucrose in the management of anemia in gynecological and obstetrical practice. Obstet Gynaecol India. 2012;62(3):281-5.

14. Aggarwal RS. Evaluation of iron sucrose and oral iron in the management of iron deficiency to in pregnancy NJCM. 2012;93:415-6.

15. Kharde PS. Comparative study of intravenous iron sucrose versus oral iron therapy in postpartum period. IJBAR. 2012;89:102-8.

16. Raja KS. Intravenous iron sucrose complex in iron deficiency anaemia in pregnancy. RWJ. 2003;216:64-9.

17. Bayoumeu F. Iron therapy in iron deficiency anaemia in pregnancy, intravenous route versus oral route. AM J Obstet Gynecol. 2002;186:518-22.

Cite this article as: Pitale DL. Effectiveness of intravenous iron sucrose over oral iron therapy for anaemia in pregnancy. Int $\mathrm{J}$ Reprod Contracept Obstet Gynecol 2018;7:1908-11. 